\title{
Bioactive Compounds in Latvian Beer
}

\author{
Ilona Dabina-Bicka*, Daina Karklina, Zanda Kruma, Fredijs Dimins \\ Department of Food Technology, LLU
}

\begin{abstract}
Beer is a complex mixture - over 400 different compounds have been characterized in beer. Significant health and product quality promoting benefits have been attributed to its bioactive secondary metabolites such as phenolics. Polyphenols and phenolic acids present in beer are natural antioxidants. The aim of the research was to characterize the bioactive compounds in Latvian barley beer, such as phenolic acids and flavanols. In an experiment, different lager-type beers produced in Latvia were analysed. The total phenolic content was determined spectrophotometrically according to the Folin-Ciocalteu colorimetric method and expressed as gallic acid equivalents. Individual phenolic compounds were determined using high performance liquid chromatography (HPLC). The antioxidant potential of beer was analyzed by the 2,2-diphenyl-1-picrylhydraziyl (DPPH) radical assays and expressed as micromoles of Trolox equivalents. The research showed that the total phenolic content of dark beer samples (320.8-863.6 mg GE L-1) was mostly higher than that of the light beers (300.9-475.2 $\mathrm{mg} \mathrm{GE} \mathrm{L}^{-1}$ ). In total, eleven phenols were determined in the analysed samples. Also the sum of individual phenolics in dark beer samples was higher than in the light beer brands. All beer samples exhibited

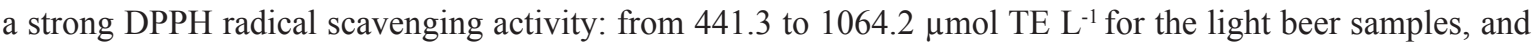

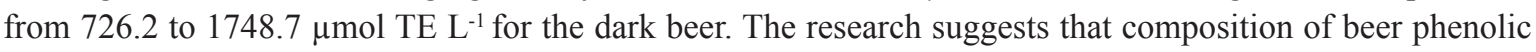
compounds was not dependent on the type of beer - light or dark.
\end{abstract}

Key words: Beer, phenolic compounds, antiradical activity.

\section{Introduction}

Beer antioxidants mainly come from the two natural ingredients used in brewing: barley and hops. The antioxidant power of beer therefore presumably depends on the antioxidant contents in ingredients and their changes during malting process, temperature and $\mathrm{pH}$ during mashing, sparing, boiling, and the variety of hops added during wort boiling and yeast fermentation (Preedy \& Rajendram, 2009).

The main antioxidant compounds in beer are phenolics and substances formed during the Maillard reaction. In addition, some additives (e.g. vitamin C) used in beer may also contribute to its antioxidant capacity (Preedy \& Rajendram, 2009). The Maillard reaction is one of the most common processes in food products. Regarding beer, the Maillard compounds are originated initially during the malting process, and later on in the extraction and boiling processes. These compounds, and especially melanoidins, influence the colour, aroma and flavour characterizing some special type of beers, and of course they also influence beer antioxidant capacity (Preedy \& Rajendram, 2009). Dark beer obviously contains more of these compounds than lager or alcohol-free beer, since it is specific that they are responsible for its characteristic colour (Rivero et al., 2005).

Phenolic composition is also one of the essential contributors for beer sensory properties - colour, flavour, astringency and bitterness was the major factor responsible for the mouth-feel differences.

Phenolic compounds play a key role as antioxidants due to the presence of a hydroxyl substitute and their aromatic structure, which enables them to scavenge free radicals. The correlation between antioxidant properties and the total phenol content has been established in several studies of wine and beer (Kruma, Karklina, Cinkmanis, \& Rutkovska, 2010; Piazzon, Forte, \& Nardini, 2010; Zhao, Chen, Lu, \& Zhao, 2010).

The most abundant phenolic acids in beer are gallic acid, ferulic acid, and syringic acid. Some of them are present in beer mainly in free forms, while others - in conjugate forms (Nardini \& Ghiselli, 2004). The concept that phenolic acid can be the most important group of food phenolic antioxidants is supported by the considerable number of papers proving that these compounds are not degraded in human gastrointestinal tract

\footnotetext{
* Corresponding author's email: 
Table 1

Physical-chemical parameters of the commercial brands of light and dark beer

\begin{tabular}{clccc}
\hline Code & \multicolumn{1}{c}{ Sample } & Alc/vol ${ }^{*} \%$ & Real extract, $\%$ & Extract of wort, $\%$ \\
\hline G1 & Cesu alus specialais & Light beer brands & & \\
G2 & Aldara Zelta & 5.2 & 3.31 & 10.65 \\
G3 & Lacplesis premium & 5.2 & 4.60 & 12.00 \\
G4 & Lacplesis Dzintara & 5.2 & 4.00 & 11.37 \\
G5 & Bauskas specialais & 4.8 & 3.57 & 10.79 \\
G6 & Piebalgas Jubilejas & 4.8 & 5.47 & 13.13 \\
G7 & Valmiermuizas nepasterizetais & 5.2 & 4.44 & 12.89 \\
G8 & Tervetes originalais & 5.2 & 5.14 & 13.01 \\
G9 & Uzavas gaisais & 5.4 & 5.47 & 13.56 \\
G10 & Laboratorijas gaisais & 4.6 & 4.35 & 11.45 \\
& & 4.5 & 4.01 & 11.20 \\
T1 & Lacplesis tris iesalu & Dark beer brands & & \\
T2 & Bauskas tumsais & 5.0 & 4.00 & 11.37 \\
T3 & Aldara ziemas tumsais & 5.5 & 7.35 & 15.82 \\
T4 & Lacplesis Kastanu tumsais & 5.8 & 7.03 & 15.92 \\
T5 & Aldaris Muiznieku tumsais & 4.8 & 3.31 & 10.98 \\
T6 & Cesu porteris & 5.0 & 4.54 & 11.97 \\
T7 & Valmiermuizas tumsais & 6.2 & 4.92 & 14.66 \\
T8 & Uzavas tumsais & 5.8 & 6.41 & 15.08 \\
\hline
\end{tabular}

* Alcohol by volume, $\%$

prior to the absorption (Ghiselli et al., 2000; Nardini, Natella, Scaccini, \& Ghiselli, 2006; Olthof, Hollman, Bujisman, Van Amelsvoort, \& Katan, 2003; Plumb et al., 1999). Beer also contains phenolic compounds of the flavonoid group such as catechin, epicatechin and quercetin, which come from the outer layers of malt and from hops (Gasowski et al., 2004). Antioxidant capacity is derived from individual bioactive compounds and also synergistic effects between them, trace elements, metals, and other food constituents (Preedy \& Rajendram, 2009). Phenolic composition is also one of the essential contributors for beer sensory properties such as colour, flavour, astringency and bitterness (Naczk \& Shahidi, 2006).

The aim of the present research is to characterize the bioactive compounds in Latvian barley beer.

\section{Materials and Methods}

The research was carried out on Latvian beers: 10 brands of light beer and 8 brands of dark beer (in Table 1 denoted as G1-G10 and T1-T8, respectively).
Physical and chemical parameters of beer samples were determined using the Alcolyzer Beer Analyzing System (Alcolyzer Plus Beer) produced by Anton Paar.

The total phenolic content (TPC) of beer was determined according to the Folin-Ciocalteu spectrophotometric method (Singleton, Orthofer, \& Lamuela-Raventos, 1999) with some modifications. Total phenols were expressed as gallic acid equivalents (GE) (Damien Dorman, Bachmayer, Kosar, \& Hiltunen, 2004).

The antioxidant activity (AA) of beer samples was measured on the basis of scavenging activities of the stable 2,2-diphenyl-1-picrylhydraziyl (DPPH) radical as outlined by Yu et al. (2003). The Trolox calibration curve was plotted as a function of the absorbance to concentration of Trolox. The final results were expressed as micromoles of Trolox equivalents (TE) per gram of dry weight ( $\mu \mathrm{mol}$ TE $\left.\mathrm{g}^{-1} \mathrm{DW}\right)$ (Zhao et al., 2008).

The concentration of all individual polyphenols was determined by HPLC Shimadzu LC-20AD 
Mobile phase gradient of the HPLC method

\begin{tabular}{ccccc}
\hline Time, & Flow rate, & \multicolumn{3}{c}{ Mobile phase, \% } \\
\cline { 3 - 5 } $\mathrm{mL} \mathrm{min}^{-1}$ & 1 & $\mathrm{~A}^{\mathrm{a}}$ & $\mathrm{B}^{\mathrm{b}}$ & $\mathrm{C}^{\mathrm{c}}$ \\
\hline Initial & 1 & 0 & 100 & - \\
$17: 50$ & 20 & 80 & - \\
\hline
\end{tabular}

${ }^{a}$ Mobile phase A: methanol

${ }^{\mathrm{b}}$ Mobile phase B: water

${ }^{c}$ Mobile phase C: acetic acid

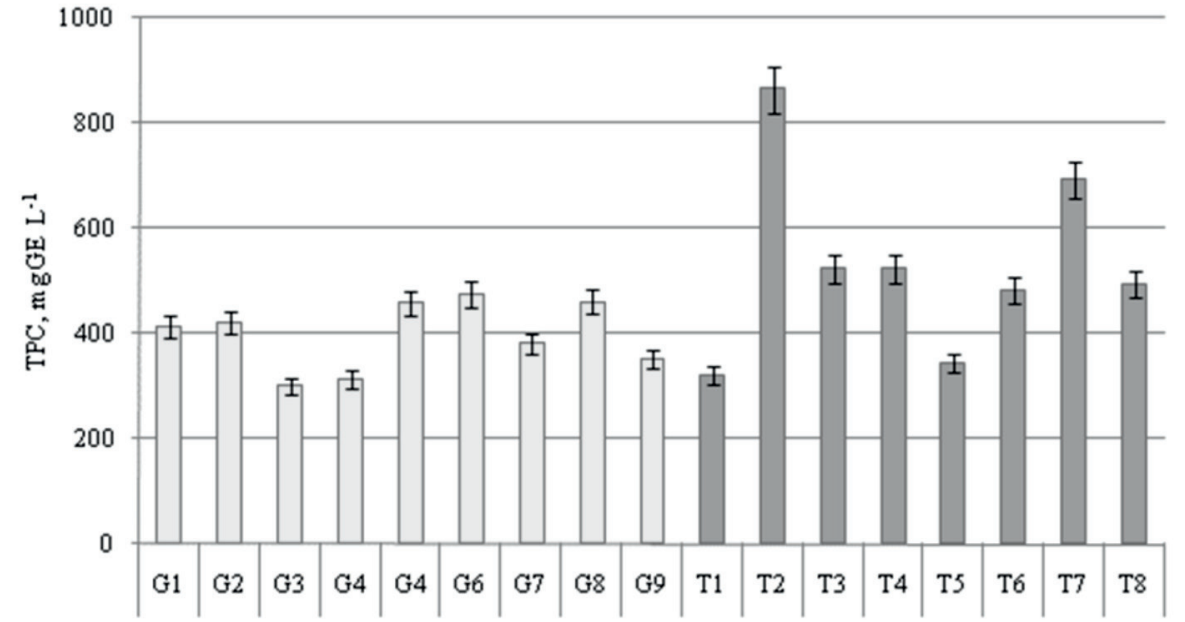

Note. The values are means of triplicate determinations \pm standard deviation.

Fig. 1. The total phenolic content of commercially produced beers.

Prominence with diode (SPD-M20A). Table 2 shows the solvent gradient used for separation.

The differences between independent groups were specified by the two-way analysis of variance (ANOVA), and the value of $p<0.05$ was regarded as statistically significant. The data obtained from the analysis of beer samples were analyzed by hierarchical cluster analysis. The dendrogram similarity scales that were generated by the SPSS program ranged between zero (grater similarity) and 25 (lower similarity).

\section{Results and Discussion}

Flavour stability, one of the most important characteristics in beer, is challenging the brewers and is one of the most important factors in determining the shelf life of packaged beer. The level of total packaged oxygen might be as low as $0.1 \mathrm{mg} \mathrm{L}^{-1}$ with a modern filling equipment, but oxidative staling of beer remains difficult to control (Bamforth, 2000). Researchers are seeking alternative ways to solve this problem by increasing the endogenous antioxidant activity of beer itself (Zhao, Chen, Lu, \& Zhao, 2010).
In our study, commercial beers were analyzed, therefore it was not possible to know the exact production technology of each beer. For this reason, four factors characterizing the beer samples were taken into account: type of beer (light or dark), alcohol content, real extract, and extract of wort (Table 1).

Polyphenols are one of the two chemical classes which influence the colloidal stability of beer (Kuntse, 2003). Eighteen beer samples investigated exhibited considerable differences in their TPC value: from $300.9 \mathrm{mg} \mathrm{GE} \mathrm{L}^{-1}$ for G3 to $863.6 \mathrm{mg} \mathrm{GE} \mathrm{L}^{-1}$ for T2. Besides, dark beer samples T7, T3 and T4 had a relatively higher TPC (>520 mg GE L ${ }^{-1}$ ) (Fig. 1). The light beers did not exceed $460 \mathrm{mg} \mathrm{GE} \mathrm{L}^{-1}$ of total phenols. The results obtained were lower than the data reported by Lugasi (2003), higher than those by Shahidi and Naczk (1995), but in accordance with the findings of Zhao, Chen, Lu, and Zhao (2010) and Piazzon, Forte, and Nardini (2010): 270-600 mg L', 60-100 $\mathrm{mg} \mathrm{L}^{-1}$, and $160-380 \mathrm{mg} \mathrm{L}^{-1}$, respectively. In our study, some samples of dark beer had a significantly higher $(p<0.05)$ amount of total phenols, 


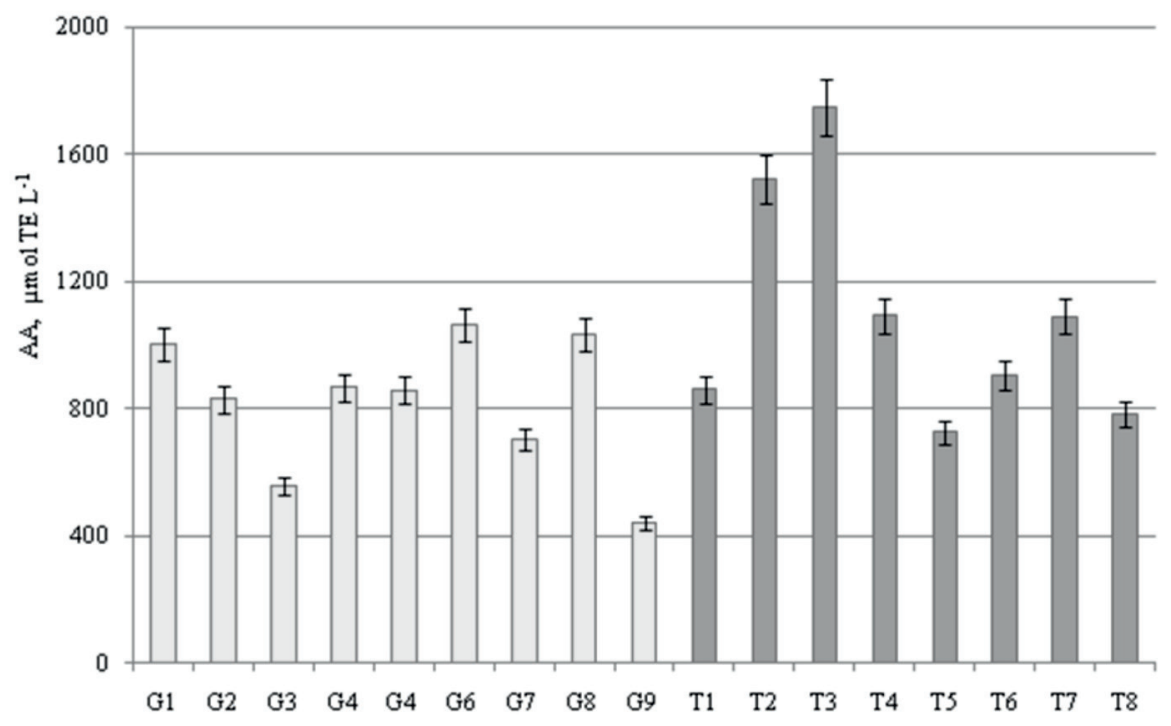

Note. The values are means of triplicate determinations \pm standard deviation.

Fig. 2. Antiradical activity of commercially produced beers.

which is in agreement with the data found in the literature (Preedy \& Rajendram, 2009).

One of the most important characteristics of polyphenolic compounds is their antiradical properties (Fig. 2). All beer samples demonstrated a strong DPPH radical scavenging activity. The highest antiradical activity was established in the dark beers samples $\mathrm{T} 2$ and $\mathrm{T} 3$ and in the light beer

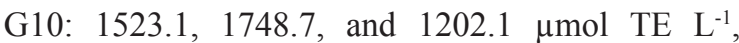
respectively. This agrees with the results obtained by Piazzon, Forte, and Nardini (2010). The value of DPPH radical scavenging activity varied from 441.3 to $1202.1 \mu \mathrm{mol} \mathrm{TE} \mathrm{L}{ }^{-1}$ for light beers and from

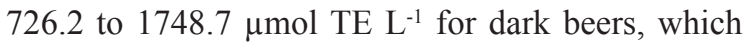
conforms to the findings of Lugasi (2003) and Zhao, Chen, Lu, and Zhao (2010) that beers exhibited a significant hydrogen-donating ability. The relatively higher sum of individual phenols in the beer samples G10, T2 and T3 might be responsible for their high DPPH radical scavenging activity. Indeed, because of their chemical structures, the caffeic acids with the highest levels in the analysed samples had significant DPPH radical scavenging activities (Brand-Williams, Cuvelier, \& Berset, 1995).

In the present study, 11 phenolic compounds were determined: nine phenolic acids and two flavanols (Table 3). In the literature, phenolic acids have been noted as powerful antioxidants in vitro and in vivo (Szwajgier \& Bancarzewska, 2011). Our study demonstrated that the content of total individual phenols in dark beer samples was higher than in the light beers. The major phenolic compounds identified in the dark beers were gallic and caffeic acids. Zhao, Chen, Lu, and Zhao (2010) have established that gallic and ferulic acids are the major phenolic constituents in beer. A number of research findings suggest that the main phenolic acid in barley, malted barley and beer is ferulic acid (Szwajgier, Pielecki, \& Targonska, 2005).

According to Montanari, Perretti, Natella, Giudi, and Fantozzi (1999), the average concentration of ferulic acid in lager-type beers evaluated by HPLC was 11.6-27.4 $\mathrm{mg} \mathrm{hl}^{-1}$, but Szwajgier, Pielecki, and Targonska (2005) have stated that ferulic acid concentration ranged between 255 and $432 \mathrm{mg} \mathrm{hl}^{-1}$. In our investigation, ferulic acid with the concentration of $1.22-9.77 \mathrm{mg} \mathrm{L}^{-1}$ was one of the four predominant phenolics detected in the analyzed beer samples. The dark beer samples T2 and T4 had both the highest and the lowest level of ferulic acid, respectively. Consequently, the type of beer - light or dark - does not have the main influence on the concentration of ferulic acid in beer.

Ferulic acid is a more effective antioxidant than catechin in a system containing hydroxyl radicals; it prevents lipid oxidation as well. It has been observed that catechin, compared to ferulic acid, causes formation of hazes in much lower concentrations (Szwajgier, Pielecki, \& Targonska, 2005). In our study, the beer samples had relatively high levels of gallic acid, catechin, caffeic acid, and ferulic acid, while the values were much lower for epicatechin, p-coumaric, syringic, sinapic, $p$-hydroxibenzoic, vanillic, and hlorogenic acids (in Table 3 - "Others"). 
The content of individual phenolics in 18 commercially produced beers, $\mathrm{mg} \mathrm{L}^{-1}$

Table 3

\begin{tabular}{|c|c|c|c|c|c|c|}
\hline Code & $\begin{array}{l}\text { Gallic } \\
\text { acid }\end{array}$ & Catechin & $\begin{array}{c}\text { Caffeic } \\
\text { acid }\end{array}$ & $\begin{array}{l}\text { Ferulic } \\
\text { acid }\end{array}$ & Others & $\begin{array}{c}\text { Sum of individual } \\
\text { phenols }\end{array}$ \\
\hline G1 & $7.56 \pm 0.03$ & $7.68 \pm 0.05$ & $7.56 \pm 0.44$ & $3.81 \pm 0.07$ & 5.35 & 31.98 \\
\hline $\mathrm{G} 2$ & $8.50 \pm 0.16$ & $9.46 \pm 0.44$ & $15.49 \pm 0.73$ & $4.37 \pm 0.08$ & 5.86 & 43.71 \\
\hline G3 & $1.95 \pm 0.02$ & $4.55 \pm 0.01$ & $8.62 \pm 0.12$ & $5.45 \pm 0.14$ & 5.27 & 25.85 \\
\hline G4 & $3.37 \pm 0.09$ & $4.18 \pm 0.01$ & $9.74 \pm 0.04$ & $3.15 \pm 0.05$ & 1.54 & 21.98 \\
\hline G4 & $20.36 \pm 0.49$ & $4.10 \pm 0.00$ & $7.28 \pm 0.01$ & $5.95 \pm 0.08$ & 1.87 & 39.54 \\
\hline G6 & $9.60 \pm 0.03$ & $0.27 \pm 0.01$ & $4.27 \pm 0.09$ & $6.05 \pm 0.05$ & 2.45 & 22.64 \\
\hline G7 & $19.27 \pm 0.94$ & $3.97 \pm 0.04$ & $2.83 \pm 0.09$ & $2.92 \pm 0.09$ & 2.44 & 31.43 \\
\hline G8 & $5.27 \pm 0.12$ & $0.91 \pm 0.05$ & $1.75 \pm 0.06$ & $7.18 \pm 0.25$ & 4.02 & 19.13 \\
\hline G9 & $17.81 \pm 0.66$ & $5.61 \pm 0.02$ & $1.05 \pm 0.05$ & $6.03 \pm 0.05$ & 3.25 & 33.75 \\
\hline G10 & $23.71 \pm 1.07$ & $2.74 \pm 0.19$ & $6.45 \pm 0.02$ & $6.14 \pm 0.16$ & 3.42 & 42.46 \\
\hline $\mathrm{T} 1$ & $14.26 \pm 0.29$ & $5.11 \pm 0.06$ & $0.58 \pm 0.03$ & $2.31 \pm 0.06$ & 3.44 & 25.70 \\
\hline $\mathrm{T} 2$ & $31.43 \pm 0.58$ & $4.16 \pm 0.03$ & $14.17 \pm 0.65$ & $9.74 \pm 0.17$ & 3.09 & 62.59 \\
\hline $\mathrm{T} 3$ & $30.44 \pm 1.65$ & $5.79 \pm 0.10$ & $24.66 \pm 0.69$ & $2.94 \pm 0.07$ & 4.70 & 68.53 \\
\hline $\mathrm{T} 4$ & $26.52 \pm 0.13$ & $2.62 \pm 0.06$ & $15.01 \pm 0.19$ & $1.23 \pm 0.01$ & 4.86 & 50.24 \\
\hline T5 & $16.04 \pm 0.04$ & $6.11 \pm 0.10$ & $24.81 \pm 1.42$ & $5.73 \pm 0.10$ & 2.14 & 54.84 \\
\hline T6 & $17.47 \pm 0.69$ & $4.38 \pm 0.07$ & $39.35 \pm 0.06$ & $5.75 \pm 0.17$ & 2.26 & 69.22 \\
\hline $\mathrm{T} 7$ & $28.82 \pm 0.23$ & $3.33 \pm 0.01$ & $7.19 \pm 0.19$ & $3.33 \pm 0.03$ & 3.38 & 46.06 \\
\hline T8 & $27.84 \pm 0.21$ & $3.80 \pm 0.11$ & $18.44 \pm 0.50$ & $3.81 \pm 0.03$ & 3.91 & 57.79 \\
\hline
\end{tabular}

Note. The values are means of triplicate determinations \pm standard deviation.

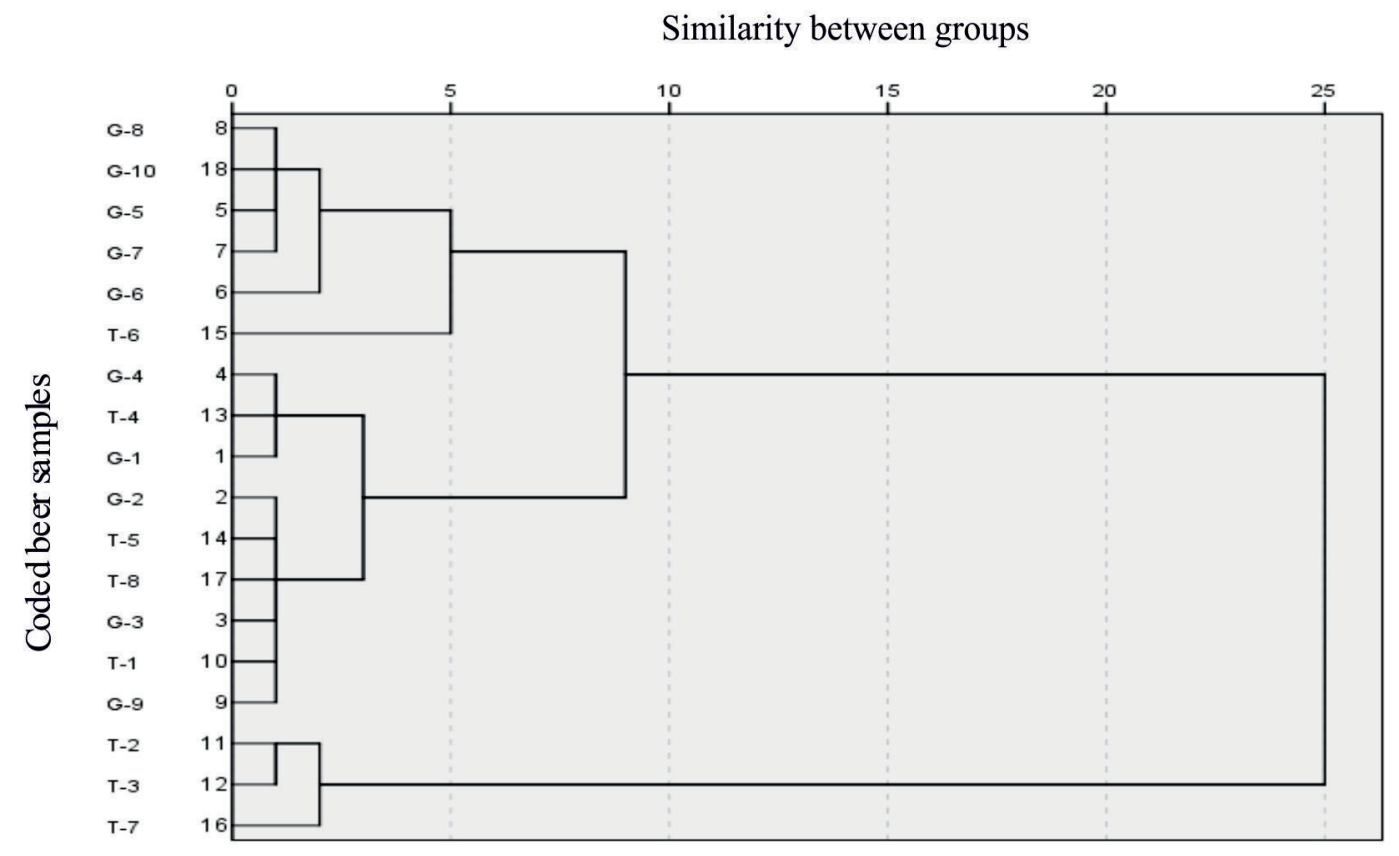

Fig. 3. The dendrogram obtained by hierarchical cluster analysis using means of the physical-chemical parameters of 18 commercially produced beers. 


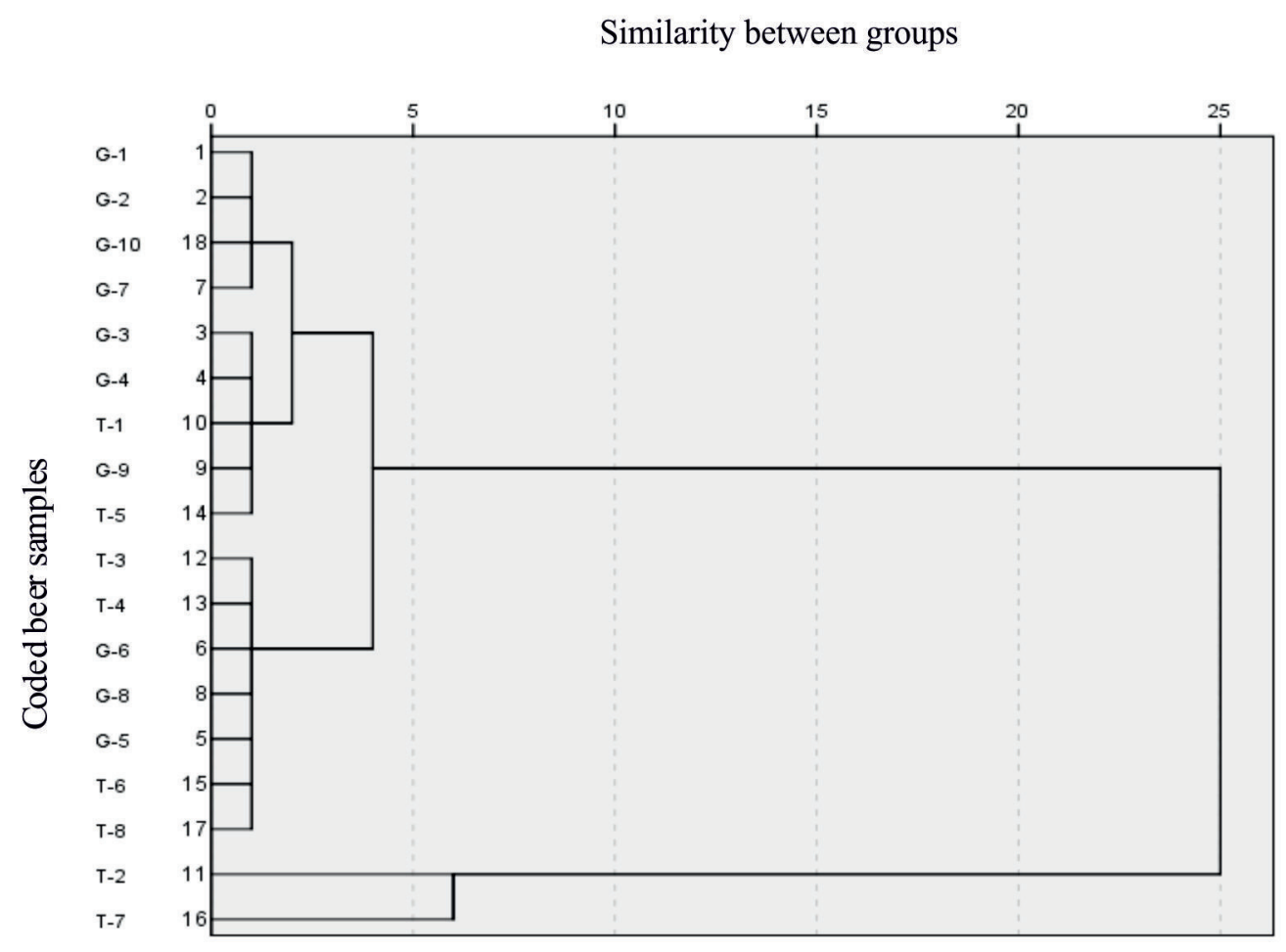

Fig. 4. The dendrogram obtained by hierarchical cluster analysis using means of the phenolic compounds of 18 commercially produced beers.

Among the different beer samples, considerable variations were found in phenolic profiles, which can be explained with the differences in raw materials, in the brewing process, and in original gravity. Piazzon, Forte, and Nardini (2010) have reported significant differences in phenolic acids content, which were influenced by beer type, with the lowest levels in dealcoholized beers and the highest levels in dark beers.

To provide similarity between the beer samples, hierarchical cluster analysis was performed. The samples were grouped taking into account the basic index (alcohol, extract of wort, real extract) (Fig. 3) and phenolic compounds (Fig. 4). Basing on the physical and chemical parameters of beers, the eighteen samples can be distributed into three general clusters:

1) G8, G10, G5, G7, G6, T6;

2) G4, T4, G1, G2, T5, T8, G3, T1, G9;

3) $\mathrm{T} 2, \mathrm{~T} 3, \mathrm{~T} 7$.

First two clusters contain both light and dark types of beer, but the third cluster - only three dark beers - T2, T3 and T7. This could be explained by the highest content both of real extract and of dry matter in first wort in the dark beer samples: 6.41-7.35\% and $>15 \%$, respectively.
Basing on the phenolic compounds, beer samples can be grouped into three clusters (Fig. 4):

1) all samples except $\mathrm{T} 2$ and $\mathrm{T} 7$;

2) $\mathrm{T} 2$;

3) $\mathrm{T} 7$.

The samples T2 and T7 are dark beers with the total phenolic content higher than in other beer samples: 863.6 and $692.0 \mathrm{mg} \mathrm{GE} \mathrm{L}^{-1}$, respectively. TPC of all other beer samples ranged between 300.9

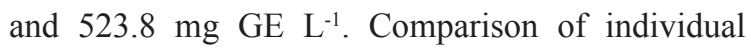
phenolic parameters among the analysed beers showed that T2 and T7 did not have the highest sum of individual phenols; however, both the samples had higher levels of gallic acid. Probably, this relevance explains why gallic acid had a greater effect on the total phenolic content.

\section{Conclusion}

Considerable variations were determined in the phenolic profile (both total and individual phenolic content) and antioxidant activities of different commercial beer brands. The obtained results show that majority of dark beer samples had a higher content of TPC and AA compared to the light beer samples. Beers with higher levels of real extract and extract of wort also exhibited higher levels of TPC 
and AA. The main phenols in the analysed beer samples were gallic, caffeic and ferulic acids and catechin. For the dark beers, the sum of individual phenolics was higher than for the light beer brands. The hierarchical cluster analysis demonstrated that compositions of beer phenolic compounds are not dependent on the type of beer - light or dark.

The present research was part of continuous efforts to improve the beer flavour stability by protecting endogenous antioxidants in beer raw material and during processing, thus increasing the amount of bioactive compounds in final beer.

\section{References}

1. Bamforth, C.W. (2000). Beer quality: Oxidation. Brewer's Guardian, 4, 31-34.

2. Brand-Williams, W., Cuvelier, M.E., \& Berset, C. (1995). Use of a free radical method to evaluate antioxidant activity. LebensmittelWissenschalf und Technologie, 28, 25-30.

3. Damien Dorman, H.J., Bachmayer, O., Kosar, M., \& Hiltunen, R. (2004). Antioxidant properties of aqueous extracts from selected Lamiaceae species grown in Turkey. Journal of Agricultural and Food Chemistry, 52, 762-770.

4. Gasowski, B., Leontowicz, M., Leontowicz, H., Katrich, E., Lojek, A., Ciz, M., ... Gorinstein, S. (2004). The influence of beer with different antioxidant potential on plasma lipids, plasma antioxidant capacity, and bile excretion of rats fed cholesterol-containing and cholesterol-free diets. The Journal of Nutritional Biochemistry, $15,527-533$.

5. Ghiselli, A., Natella, F., Guidi, A., Montanari, L., Fantozzi, P., \& Scaccini, C. (2000). Beer increases plasma antioxidant capacity in humans. The Journal of Nutritional Biochemistry, 11, 76-80.

6. Kruma, Z., Karklina, D., Cinkmanis, I., \& Rutkovska, O. (2010). Polyphenolic composition and free radical scavenging activity of red wines available in the Latvian market. Chemine technologija, 1(54), 56-61.

7. Kuntse, V. (2003). Technology of malt and beer. St. Petersburg: Professiya. (In Russian.)

8. Lugasi, A. (2003). Polyphenol content and antioxidant properties of beer. Acta Alimentaria, $32,181-182$.

9. Montanari, L., Perretti, G., Natella, F., Giudi, A., \& Fantozzi, P. (1999). Organic and phenolic acids in beer. Lebensmittel-Wissenschalf und Technologie, 32, 535-539.
10. Naczk, M., \& Shahidi, F. (2006). Phenolics in cereals, fruits and vegetables: Occurrence, extraction and analysis. Journal of Pharmaceutical and Biomedical Analysis, 41(5), 1523-1542.

11. Nardini, M., \& Ghiselli, A. (2004). Determination of free and bound phenolic acid in beer. Food Chemistry, 84(1), 137-143.

12. Nardini, M., Natella, F., Scaccini, C., \& Ghiselli, A. (2006). Phenolic acids from beer are absorbed and extensively metabolized in humans. Journal Nutrition and Biochemistry, 17, 14-22.

13. Olthof, M.R., Hollman, P.C., Bujisman, M.N., Van Amelsvoort, J.M., \& Katan, M.B. (2003). Clorogenic acid, quercitin-3-rutinoside and black tee phenols are extensively metabolised in human. The Journal of Nutrition, 133, 18061814.

14. Piazzon, A., Forte, M., \& Nardini, M. (2010). Characterization of phenolics content and antioxidant activity of different beer types. Journal of Agriculture and Food Chemistry, 58, 10677-10683.

15. Plumb, G.W., Garcia-Conesa, M.T., Kroon, P.A., Rhodes, M., Rigley, S., \& Williamson, G. (1999). Metabolism of clorogenic acid by human plasma, liver, intestine and gut microflora. Journal of Scince and Food Agriculture, 79, 390-392.

16. Preedy, V.P., \&Rajendram, R. (2009). Ethanol in beer: Production, absorption and metabolism. In V.P. Preedy (Ed.), Beer in health and disease prevention (pp. 429-440). Burlington, MA; San Diego, CA; London: Elsevier/Academic Press.

17. Rivero, D., Perez-Magarino, S., GonzalezSanjose, L., Valls-Belles, V., Codoner, P., \& Muniz, P. (2005). Inhibition of induced DNA oxidative damage by beers: Correlation with the content of polyphenols and melanoidins. Journal of Agriculture and Food Chemistry, 53(9), 3637-3642.

18. Shahidi, F., \& Naczk, M. (1995). Phenolic compounds of beverages. In Food phenolics: Sources, chemistry, effects, applications (pp. 128-136). Lancaster, PA: Technomic Publishing Company, Inc.

19. Singleton, V.L., Orthofer, R., \& LamuelaRaventos, R.M. (1999). Analysis of total phenols and other oxidation substrates and antioxidants by means of Folin-Ciocalteu reagent. Methods in Enzymology, 29, 152-178.

20. Szwajgier, D., \& Bancarzewska, M. (2011). Changes in the phenolic acid content during 
wort boiling and whirlpool. Acta Scientiarum Polonorum Technologia Alimentaria, 10(1), 19-33.

21. Szwajgier, D., Pielecki, J., \& Targonska, Z. (2005). The release of ferulic acid and feruloylated oligosaccharides during wort and beer production. Journal of the Institute of Brewing, 111(4), 372-379.

22. Yu, L., Haley, S., Perret, J., Harris, M., Wilson, J., \& Haley, S. (2003). Antioxidant properties of bran extracts from Akron wheat grown at different locations. Journal of Agriculture and Food Chemistry, 51, 1566-1570.

23. Zhao, H., Chen, W., Lu, J., \& Zhao, M. (2010). Phenolic profiles and antioxidant activities of commercial beers. Food Chemistry, 119, 1150-1158.

24. Zhao, H., Fan, W., Dong, J., Lu, J., Chen, J., Shan, L., ... Kong, W. (2008). Evaluation of antioxidant activities and total phenolic contents of typical malting barley varieties. Food Chemistry, 107, 296-304.

\section{Acknowledgements}

The research has been prepared within the framework of the ESF Project "Formation of the Research Group in Food Science”, Contract No. 2009/0232/1DP/1.1.1.2.0/09/APIA/VIAA/122, and the State Research Programme "Sustainable Use of Local Resources (Entrails of the Earth, Food, and Transport) - New Products and Technologies (NatRes)" (2010-2013), Project No. 3 "Sustainable use of local agricultural resources for development of high nutritive value food products (Food)". 